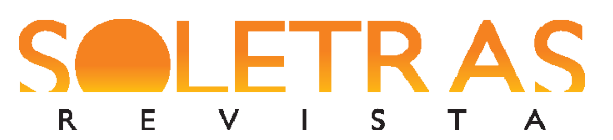

\title{
O Efeito da Lacuna Preenchida na posição de sujeito no português brasileiro $^{1}$
}

\author{
Fernando Lúcio de Oliveira ${ }^{2}$
}

Resumo: Este artigo trata do processamento on-line de interrogativas-QU de sujeito e de objeto. Utilizou-se a técnica de leitura automonitorada não cumulativa para investigar se o maior custo cognitivo associado ao Efeito da Lacuna Preenchida (CRAIN; FODOR, 1985; STOWE, 1986) na posição de objeto em trabalhos anteriores (MAIA, 2014, MAIA; MOURA; OLIVEIRA, 2014, MAIA; MOURA; SOUZA, 2016) seria aferido também na posição de sujeito em frases do tipo objeto-sujeitoverbo (OSV) no português brasileiro. Os resultados apontam um ñefeito surpresaò na lacuna preenchida de sujeito, indicando que o fenômeno se instancia na língua, como previsto.

Palavras-chave: Efeito da lacuna preenchida. Sintagmas-QU. Assimetria sujeito-objeto. Processamento.

\section{Introdução}

O chamado Efeito da Lacuna Preenchida (Filled-Gap Effect) vem sendo estudado em várias línguas desde os clássicos trabalhos de Crain \& Fodor (1985) e Stowe (1986) com frases do inglês. O primeiro trabalho utilizou a técnica de leitura automonitorada para investigar frases como (1):

(1) a. Who had the little girl expected $u s$ to sing those stupid French songs for _ at Christmas?

b. The little girl had expected $u s$ to sing those stupid French songs for Cheryl at Christmas?

A diferença crucial aqui é que (1b) é uma declarativa e (1a), uma interrogativa com um sintagma-QU movido. Medindo os tempos de leitura para us nas duas frases, os tempos médios de leitura foram significativamente maiores para a primeira em relação à segunda, indicando que quando há um traço QU não interpretado na sentença o leitor espera uma lacuna e não um sintagma nominal. Por isso, a presença de um sintagma ocupando a posição de objeto do verbo expected, no primeiro caso (1a), causa reanálise e aumenta os tempos de processamento.

\footnotetext{
${ }^{1} \mathrm{O}$ experimento aqui reportado ajuda a compor a tese de doutorado do autor (OLIVEIRA, 2017[no prelo]) e seus resultados estão discutidos aqui à luz de novos insights.

${ }^{2}$ Professor Substituto de Linguística na Faculdade de Letras da UFRJ, RJ, Brasil. fernandolucioufrj@gmail.com.
} 


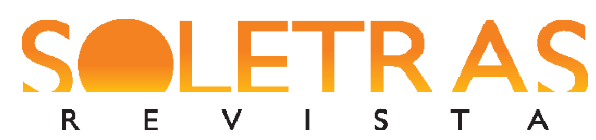

Stowe (1986) realiza dois experimentos de leitura automonitorada com frases do inglês, dos quais se reporta aqui o primeiro. A autora observa que Crain \& Fodor (1985) trouxeram evidências de que um efeito ocorre na lacuna de objeto (em $u s$ ) nas frases em (1), mas não demonstraram que todos os tipos de posição ocupáveis por um sintagma nominal (SN) são tratados do mesmo modo em procedimentos que envolvem a localização de lacunas. Partindo de uma sentença base do tipo if-clause, são elaborados os itens como os exemplificados em (2):

(2) a. IF-CLAUSE: My brother wants to know if Ruth bring us home to Mom at Crhistmas.

b. WH-SUBJ: My brother wants to know who__ bring us home to Mom at Crhistmas.

c. WH-OBJ: My brother wants to know who Ruth will bring _ home to Mom at Crhistmas.

d. WH-POBJ: My brother wants to know who Ruth will bring us home to at Crhistmas.

As três regiões de interesse estão destacadas em negrito. Em WH-SUBJ, há um SN ausente, uma posição vazia (lacuna) e o sintagma-QU who é candidato a ser interpretado naquela posição. A localização da lacuna para who poderia ser feita também na posição de objeto do verbo bring (WH-OBJ) ou na posição de complemento da preposição to (WHPOBJ). Uma das questões entretidas era se o efeito encontrado por Crain \& Fodor na comparação interrogativas-QU x declarativas seria replicado comparando-se este tipo de frases às sentenças com if. Outra motivação para o estudo era verificar se lacunas de sujeito preenchidas por um SN pleno também causariam os efeitos encontrados por esses autores.

Os resultados indicam tempos de leitura significativamente mais altos para us em WHPOBJ do que em IF-CLAUSE, o que foi interpretado como um efeito surpresa, o Efeito da Lacuna Preenchida (ELP): a posição ocupada por us seria a primeira lacuna ótima para o preenchimento pelo sintagma-QU movido, expectativa quebrada quando o parser $^{3}$ encontra a posição ocupada. Comparando os tempos de leitura de Ruth em WH-SUBJ e WH-OBJ, não houve diferença significativa. A autora interpreta o resultado como evidência de que não há expectativa sobre a lacuna na posição de sujeito, comentando haver duas possíveis explicações: (a) não haveria expectativa sobre a lacuna de sujeito e a procura por uma lacuna iniciaria somente quando um SN pleno fosse identificado, informando que há um sintagma-

3 Também referido na literatura psicolinguística como ñmecanismo humano de processamento de frasesò (cf. MAIA \& FINGER, 2005). 


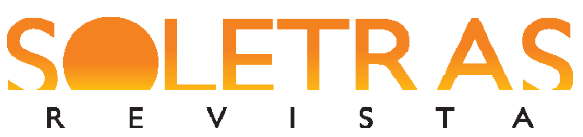

QU movido sem papel temático ou (b) tanto sujeito quanto objeto geram expectativa, mas é mais fácil corrigir a expectativa no caso de um SN ser encontrado na lacuna de sujeito (o que se refletiria em tempos baixos) do que na de objeto (o que se refletiria em tempos altos).

Neste artigo, argumenta-se que a explicação (b) parece falsa, uma vez que a resolução de procedimentos envolvendo a interpretação de cadeias-QU obedece a uma heurística de imediaticidade e não poderia atrasar a postulação de um sintagma-QU a uma lacuna mais próxima, seja de sujeito ou de objeto, em consonância com princípios de parsing propostos após o trabalho de Stowe no âmbito da Teoria do Garden-Path, tais como o Princípio do Antecedente Ativo (PAA ï FRAZIER \& CLIFTON, 1989) e o Princípio da Cadeia Mínima (PCM Ï DE VINCENZI, 1991; 1996). Embora o Efeito da Lacuna Preenchida não tenha sido demonstrado em lacunas de sujeito no caso de interrogativas-QU encaixadas, resultados prévios obtidos a técnica de leitura automonitorada (OLIVEIRA; MAIA, 2010, OLIVEIRA, 2013) advogariam em favor de que efeitos de estranhamento pela presença de um item preenchendo a posição de sujeito em interrogativas-QU do PB foram, de fato, encontrados.

Doravante, o artigo está organizado da seguinte maneira: a seção 1 resenha trabalhos recentes sobre o Efeito da Lacuna Preenchida no português brasileiro. A seção 2 pondera sobre um possível Efeito da Lacuna preenchida na posição de sujeito, com base nas conclusões de Stowe (1986). Em 3, são apresentados e discutidos os resultados de um experimento de leitura automonitorada com interrogativas-QU do português, seguindo-se as conclusões e as referências.

\section{O Efeito da Lacuna Preenchida no português brasileiro}

Nos últimos três anos, vários trabalhos têm sido conduzidos na pesquisa psicolinguística sobre o português brasileiro para aferir em tempo real a instanciação de fenômenos sintáticos e a satisfação de condições gramaticais na fase on-line do curso temporal de processamento. Um dos debates em desenvolvimento é sobre a ocorrência de ñilusões gramaticaisò e efeitos de ñfalibilidade seletivaò discutidos por Phillips et.al. (2011). Para os autores, assim como foi importante reconhecer a existência de ilusões de ótica para compreender a percepção visual, ilusões gramaticais precisam ser explicadas para melhor 


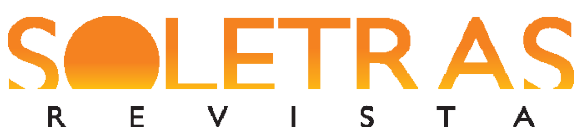

compreensão de ñcomo os falantes codificam e navegam representações linguísticas em tempo realò.

Uma contribuição importante para essa discussão foi apresentada em Maia, Moura \& Oliveira (2014). Nele investigamos se o parser cometeria falhas em contextos gramaticais específicos e se essa falibilidade seria seletiva, no sentido de ocorrer em algumas situações e não em outras. Utilizamos a técnica de leitura automonitorada para investigar o processamento de lacunas em frases como (3) ï rótulos das condições ao início (como nos demais experimentos reportados no artigo):

a. CTN Que rede o pescador usou terça sem lançar com força na praia?

b. DTN Que rede o pescador usou sem lançar com força terça na praia?

c. CTAdv Que rede o pescador usou ontem sem lançar com força na praia?

d. DTAdv Que rede o pescador usou sem lançar com força ontem na praia?

A hipótese era de que se o parser sofresse uma ilusão gramatical, iria apor ñterçaò (um SN em função adverbial) como objeto do verbo usou na frase (3a). Assim, os tempos seriam significativamente maiores para ñterçaò em (3a) em comparação a esse mesmo item na frase (b). O Princípio do Antecedente Ativo (CLIFTON \& FRAZIER, 1989) levaria o parser a uma busca ativa por uma lacuna (gap as a first resort) e ele seria iludido por um Efeito da Lacuna Preenchida (ELP) falso refletido em latências maiores. A mesma diferença não era esperada para a leitura de ñontemòem (3c) x ñontemò em (3d), já que se trata de um advérbio real e não um nome em função adverbial. Esperava-se que o advérbio não levasse o parser a uma ilusão gramatical e os tempos médios fossem semelhantes.

Questionando se o mesmo seria verificado no caso de verbos intransitivos, elaborou-se um novo conjunto de frases. No caso das frases em 3, havia verdadeiramente uma lacuna, subcategorizada pelo verbo, a ser preenchida, mas nas frases em (4) não. Diante disso, o parser postularia um ñpreenchedor ilusórioò de lacuna inexistente, como nos exemplos abaixo?

(4) a. CIN Que rede o pescador caiu terça ao lançar com força na praia?

b. DIN Que rede o pescador caiu ao lançar com força terça na praia?

c. CIAdv Que rede o pescador caiu ontem ao lançar com força na praia?

d. DIAdv Que rede o pescador caiu ao lançar com força ontem na praia? 


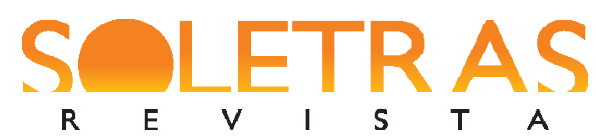

Como um verbo intransitivo não projeta posição de complemento, a expectativa era de que se o parser tivesse acesso à grade argumental do verbo, não postularia lacuna após um verbo como ñcairò nos exemplos, assim os tempos não iriam diferir muito. Por outro lado, se a grade argumental do verbo não for inspecionada na busca pela lacuna, os tempos de leitura para terça em CIN serão maiores do que a leitura desse mesmo item em DIN, demonstrando que haveria ELP mesmo onde, a rigor, não há lacuna de objeto, refletindo uma ilusão gramatical do parser também diante de verbos intransitivos.

Os resultados incluem a conclusão de que um nome em função adverbial (como terça, nos exemplos) é postulado como antecedente da lacuna de um verbo transitivo, tendo sido obtidas diferenças estatisticamente significativas na comparação entre (3a) CTN 664ms e (3b) DTN $483 \mathrm{~ms}\left(\mathrm{t}(47)=3.00 \mathrm{p}<0.0043^{*}\right)$, o que evidencia a instanciação do ELP no português brasileiro. Observou-se também que a comparação entre (4a) e (4b) não foi estatisticamente significativa: CIN $(618,6 \mathrm{~ms})$ x DIN $(584,2 \mathrm{~ms})(\mathrm{t}(47)=1.19 \mathrm{p}<0.2391 \mathrm{~ns}$, assim como a comparação entre (4c) e (4d): CIAdv (609,9ms) x DIAdv (635,5ms) t(47)=1.23 p< 0.2248ns). Isso indicaria acesso do parser à informação sobre grade argumental do verbo, o que faz com que a lacuna não seja postulada após um verbo intransitivo, evitando a ilusão gramatical verificada nos verbos transitivos. Os resultados, desse experimento, portanto, sugerem que o parser está sujeito a falências de análise na postulação de lacunas e que a falibilidade do parser é seletiva, sensível a restrições e contextos de natureza gramatical.

Outro experimento realizado recentemente foi discutido em Maia (2014a). Partindo de Traxler \& Pickering (1996), que utilizam a técnica de rastreamento ocular para investigar efeitos de plausibilidade no processamento em frases como (5):

(5) a. Thatô the pistol with which the heartless killer shot the hapless man...

b. Thatôs the garage with which the heartless killer shot the hapless man...

Os autores detectam tempos maiores de fixação em (5b) e argumentam que o efeito é devido à implausibilidade de se usar garagem como instrumento do verbo to shoot, por isso essa diferença seria detectada durante (ou imediatamente após) a leitura do verbo. Com base nesse resultado e nos de Maia, Moura \& Oliveira (2014), Maia (2014a) elabora dois experimentos: um de rastreamento ocular e um de leitura automonitorada, com o objetivo de 
investigar o Efeito da Lacuna Preenchida (ELP) e seu acesso semântico no processamento de frases do português brasileiro (PB) por meio dessa técnica. O experimento (1) testou frases como as de (6):

(6) a. [G] Que livro o professor escreveu _ sem ler a tese antes?

b. [F] Que livro o professor escreveu a tese sem ler antes?

A expectativa era de que o tempo total de fixação na região de interesse ( $\mathrm{SN}$ a tese) na frase com a lacuna preenchida $[\mathrm{F}]$ seria significativamente maior que o desse mesmo $\mathrm{SN}$ em uma posição em que não intervém na interpretação do sintagma movido, após uma lacuna [G] e mais acertos nas perguntas interpretativas ${ }^{4}$ em $[\mathrm{G}]$ do que em [F]. Os resultados seguem a direção esperada.

O segundo experimento, de leitura automonitorada, acrescentou o fator plausibilidade semântica no design, gerando as condições exemplificadas nas frases abaixo:
a. [GP] Que livro o professor escreveu _ sem ler a tese antes?
b. [FP] Que livro o professor escreveu a tese sem ler antes?
c. [GI] Que livro o professor cozinhou __sem ler a tese antes?
d. [FI] Que livro o professor cozinhou a tese_ sem ler antes?

As expectativas incluíam a replicação do efeito encontrado no experimento 1 (rastreamento ocular), a saber, maiores tempos para a tese em (7b) do que para esse mesmo item em (7a). Além disso, se o parser não acessa a informação sobre a plausibilidade semântica sobre o verbo ñcozinhouò, os tempos para ña teseò na condição (7d) serão maiores que na condição (7c). Esperavam-se também maiores índices de erros para (7b) e (7d) em comparação a (7a) e (7c), respectivamente. Os resultados para a comparação (7b) x (7a) foram estatisticamente significativos, semelhantes ao do experimento 1.

Um achado importante desse segundo experimento foi que, em direção oposta ao resultado de Traxler \& Pickering (1996), foram encontrados tempos significativamente maiores para a tese em (7d) comparados aos tempos de a tese em (7c), evidência de que o ELP se instancia nesse contexto, mesmo sendo semanticamente implausível atribuir ña teseò

\footnotetext{
${ }^{4} \mathrm{Em}$ ambos os casos, a pergunta ao final da frase era ñO que o professor escreveu?ò e as opções de respostas eram ño livroò e ña teseò.
} 


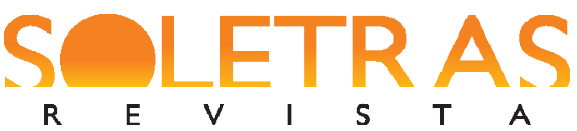

como objeto do verbo ñcozinharò. Também foram obtidos índices de acerto significativamente maiores para as condições plausíveis (GP e FP) do que para as implausíveis (GI e FI), sugerindo que o efeito de plausibilidade não verificado na medida online é capturado na fase interpretativa. Maia (2014a) conclui que o parser atua de modo a preferir rapidamente a postulação da primeira lacuna disponível tanto nos resultados do rastreamento ocular quanto nos resultados com a leitura automonitorada e o efeito de plausibilidade semântica só é instanciado na fase off-line (evidência em favor de modelos syntax first).

\section{Efeito da Lacuna Preenchida na posição de sujeito}

O experimento de Stowe (1986) reportado na introdução utiliza a técnica de rastreamento ocular para investigar o processamento de lacunas de objeto em frases como as de (2) retomadas abaixo:

a. IF-CLAUSE: My brother wants to know if Ruth bring us home to Mom at Crhistmas.

b. WH-SUBJ: My brother wants to know who_ bring us home to Mom at Crhistmas.

c. WH-OBJ: My brother wants to know who Ruth will bring _ home to Mom at Crhistmas.

d. WH-POBJ: My brother wants to know who Ruth will bring us home to at Crhistmas.

Como visto, a autora não encontra diferenças significativas para a leitura de Ruth comparando os tempos médios de leitura das frases acima, concluindo que não há expectativa para a lacuna de sujeito, pois não há efeito surpresa para a lacuna preenchida por Ruth em (2c, d). Nesse caso, seguindo-se o princípio metodológico da evidência positiva, a ausência de evidência nesse experimento em favor de um efeito na posição do sujeito não é suficiente para excluir a possibilidade de que ele exista ${ }^{5}$. Sendo encontradas evidências positivas, como as apresentadas na seção 3, devem prevalecer.

A autora pondera que ñuma possibilidade é que não se gera expectativa sobre a lacuna de sujeito. Outra é a de que tanto sujeito quanto objeto geram expectativa, mas é mais fácil corrigir a expectativa no caso de um SN ser encontrado na lacuna de sujeito do que na de

\footnotetext{
${ }^{5}$ Raciocínio consubstanciado na frase ñA ausência de evidência não constitui evidência da ausênciaò, atribuída ao Carl Sagan (1934-1996), professor de astronomia e ciências espaciais na Universidade de Cornell, nos Estados Unidos.
} 


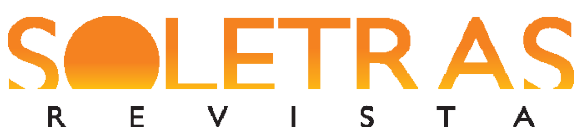

objetoò (p. 238). A primeira possibilidade equivaleria a dizer que o parser procrastina a tarefa de postular a cadeia imediatamente, indo contra o Princípio do Antecedente Ativo (CLIFTON \& FRAZIER, 1989), o qual postula a lacuna como primeiro recurso (gap as a first resort) e indicaria que não há evidência de realidade psicológica para o processamento on-line da lacuna de sujeito. A segunda implica que efeitos de interveniência de outros itens entre o sujeito-QU e o verbo aumentariam tanto os tempos de processamento. Resultados sobre assimetria sujeito-objeto no PB (OLIVEIRA \& MAIA, 2010, OLIVEIRA, 2013, OLIVEIRA, 2017) e os que são discutidos na seção 3 deste artigo advogam contra ambas as hipóteses.

Maia (2014a) lembra que ELP já foi demonstrado em diversas línguas além do inglês, como o holandês (FRAZIER, 1987), o italiano (VICENZI, 1991), o húngaro (RADÓ, 1999), entre outras línguas. Esses e outros trabalhos tratam mais propriamente do Efeito da Lacuna Preenchida na posição de objeto, assim como os trabalhos reportados aqui sobre o PB e há também interesse em aferir que tipos de assimetrias de processamento não previstas na Teoria Gramatical, como a atribuição de papel temático, no que tem sido chamado Efeito da Lacuna Ativa (MAIA, 2014b) entre outros. Interessante notar, porém, que não parece ter sido ainda investigado experimentalmente em PB se o fenômeno se instanciaria em lacunas de sujeito.

Estudos sobre o PB demonstram maior dificuldade de processamento para o objeto do que para o sujeito, por exemplo, em interrogativas-QU e orações relativas (cf. GOUVEA, 2005, OLIVEIRA \& MAIA, 2010, OLIVEIRA, 2013). O mesmo se espera em relação a frases como (8), típicas do PB, que envolvem um sujeito interveniente entre o sintagma-QU objeto e o verbo da sentença:

a. Que bolsista ${ }_{[0 b j e t o]}$ a caloura ${ }_{[\text {sujeito] }}$ convidou no baile?
b. Que bolsista $a_{[\text {[ujeito] }}$ convidou a caloura $a_{[o b j e t o]}$ no baile?

Note-se que ambas as frases possuem os mesmos itens lexicais. $\mathrm{O}$ que as diferencia linearmente é a ordem de constituintes: (8a) é objeto-sujeito-verbo (OSV) e (8b) é sujeitoverbo-objeto (SVO), ordem canônica no PB. Observando, porém, essas mesmas frases no que diz respeito à postulação de lacunas pelo parser, ambas possuem o mesmo sintagma-QU movido para a chamada Periferia Esquerda da sentença (CHOMSKY, 1977), que precisam de uma lacuna para que seu papel temático seja interpretado. No início da frase, a leitura de Que 


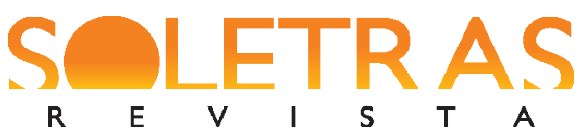

bolsista dispara uma busca pela primeira lacuna possível (de acordo com o já referido Princípio do Antecedente Ativo), que pode ser tanto sujeito quanto objeto. No português, a primeira lacuna disponível em uma típica sentença SVO é a de sujeito, logo antes do verbo, como se observa em (9):

\section{Que bebida_aqueceu__ o turista no inverno?}

Se a lacuna de sujeito está disponível, não há efeito, visto que o sintagma-QU é interpretado naquela posição. Se está preenchida por um sintagma nominal, como a caloura em (8a), a questão que se coloca é se não deveria haver um reflexo em tempos maiores de processamento. Ora, observando os itens usados por Stowe (1986) no experimento 1 (frases em (2)), todas as frases apresentam uma oração matriz ñMy brother wants to knowò e uma oração encaixada, que pode ser introduzida por who ou por if. A ausência do efeito nas frases em (2) pode ser devida, por exemplo, a alguma peculiaridade envolvendo orações encaixadas do inglês, no caso, interrogativas-QU indiretas. Convém, portanto, que o fenômeno seja investigado em construções desse tipo e, sobretudo em outros contextos gramaticais, envolvendo não só lacunas de objeto, mas também de sujeito, por exemplo, em interrogativasQU diretas do português brasileiro, que envolvem inversão sintática em frases como (8), equivalentes às utilizadas em um experimento para o português europeu (cf. OLIVEIRA, 2017[no prelo]):

a. Que bolsista _convidou a caloura no baile?
b. Que bolsista a caloura convidou _no baile?

Se não há expectativa sobre a lacuna de sujeito em uma frase como (10a), os tempos de leitura para a caloura em ambas as frases não deverão apresentar diferenças significativas, replicando os resultados de Stowe (1986). Se a expectativa é gerada, como argumentado aqui, um efeito surpresa será verificado na posição do sintagma interveniente na frase (10b).

Com o objetivo de discutir essa questão, são apresentados e discutidos a seguir os resultados de um experimento de leitura automonitorada com interrogativas-QU do PB, com frases semelhantes a (10). 


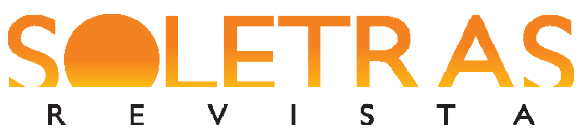

\section{Experimento de leitura automonitorada}

Elaborou-se um experimento de leitura automonitorada com frases do PB (self-paced reading), com julgamento de pergunta interpretativa, cujo objetivo é investigar a relação entre função sintática e congruência semântica e explorar se um Efeito da Lacuna Preenchida (ELP) ocorreria em uma posição onde um sintagma-QU sujeito poderia ser interpretado.

\subsection{Desenho Experimental e Materiais}

Desenvolveu-se um design 2x2 within subjects com dois fatores de dois níveis cada: Função Sintática (sujeito[S]/objeto[O]) e Congruência Semântica (congruente $[\mathrm{C}]$ /incongruente $[\mathrm{I}]$ ). Os tempos médios de leitura (medida on-line $і ̈$ em milésimos de segundo) no segmento crítico (a caloura) e a acurácia nas respostas às perguntas finais (medida off-line ï número de acertos [sim/não]) foram as variáveis dependentes.

Do cruzamento das variáveis independentes, formou-se o seguinte quadro de condições experimentais:

\begin{tabular}{|c|c|c|c|c|c|}
\hline CÓDIGO & SEG1 & SEG2 & SEG3 & SEG4 & LEGENDA \\
\hline QSC & Que bolsista & convidou & a caloura & no baile? & QU Sujeito, Congruente \\
\hline QOC & Que bolsista & a caloura & convidou & no baile? & QU Objeto, Congruente \\
\hline QSI & Que celular & convidou & a caloura & no baile? & QU Sujeito, Incongruente \\
\hline QOI & Que celular & a caloura & convidou & no baile? & QU Objeto, Incongruente \\
\hline
\end{tabular}

Quadro 1: exemplos de condições experimentais.

Foram utilizados 48 conjuntos de 4 estímulos (48 x 4 =192) experimentais no total, distribuídos nas 4 versões do experimento, somados a 72 frases distrativas, comuns em todas as versões. Cada versão contou, pois, com 120 frases (48 experimentais +72 distrativas), divididas em 3 blocos de 40 frases cada.

Após os segmentos da frase terem sido lidos, uma pergunta interpretativa surgia na tela, com duas opções de resposta: 


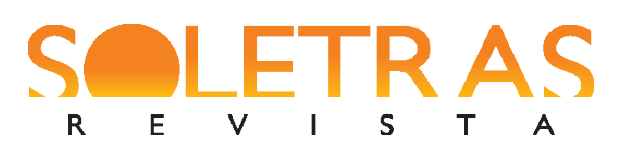

N. 33 ï 2017.1 ï FERNANDO LÚCIO DE OLIVEIRA

\begin{tabular}{|c|c|c|c|c|c|c|}
\hline SEG1 & SEG2 & SEG3 & SEG4 & PERGUNTA & OPÇÃO 1 & OPÇÃO2 \\
\hline Que bolsista & convidou & a caloura & no baile? & Quem convidou? & O bolsista & a caloura \\
\hline
\end{tabular}

Quadro 9: exemplo de item experimental

Os dezesseis participantes eram todos alunos de graduação ou mestrado da Faculdade de Letras da Universidade Federal do Rio de Janeiro e foram testados isoladamente na sala do Laboratório de Psicolinguística Experimental (LAPEX/UFRJ). Todos eles participaram previamente de uma pequena prática do experimento e assinaram um Termo de Consentimento Livre e Esclarecido concordando com a realização da tarefa.

\subsection{Procedimento}

O procedimento funcionou da seguinte maneira: o participante passava por uma versão de treinamento, contendo 10 frases. Depois, uma tela de intervalo anunciava que a barra de espaço deveria ser pressionada para começar o experimento de fato. Feito isso, um bloco com 120 frases (48 experimentais +72 distrativas), já distribuídas em quadrado latino, era apresentado, randomizado e dividido em 3 sub-blocos, com 40 frases cada. Ao final de cada sub-bloco, aparecia uma mensagem de intervalo. Por fim, uma mensagem de fim era apresentada. A sequência do bloco experimental ocorria no E-Prime (versão 2.0 para Windows) da seguinte maneira: cruz de fixação »» segmento1 »» segmento2 »» segmento3 »» segmento4 »» pergunta. Os tempos-limite para cada segmento foram definidos como "infinito" e o participante foi orientado no treinamento a avançar os segmentos evitando lentidão ou precipitação.

\subsection{Hipóteses e Previsões}

O objetivo era colher resultados que permitissem a comparação entre o comportamento do parser diante de sentenças interrogativas-QU de sujeito e de objeto congruentes e incongruentes nessas duas línguas. A literatura aponta maior custo cognitivo para frases com sintagmas-QU de objeto em diversos campos, como em estudos de aquisição da linguagem (CEREJEIRA, 2009, LOBO et.al., 2014), processamento de clivadas (ALVES 
et.al., 2015), processamento de orações relativas (GOUVEA, 2005, OLIVEIRA \& MAIA, 2010, OLIVEIRA, 2013), entre outros. Porém, nenhum deles, aparentemente, relaciona os resultados a um possível efeito surpresa para o preenchimento de uma lacuna de sujeito, de onde um sintagma-QU pudesse ter sido extraído.

As previsões incluíam maiores índices de acerto nas perguntas interpretativas e menores tempos médios de leitura para as interrogativas-QU de sujeito (QSC e QSI) do que para as interrogativas-QU de objeto (QOC e QOI). Se verificado, o efeito surpresa acontecerá no segundo segmento de frases do tipo QOC, as quais são, na verdade, interrogativas-QU de objeto. Entreteve-se a hipótese de que, se a primeira lacuna deve ser postulada e as interrogativas-QU no PB são tipicamente SVO, ao encontrar um sintagma como Que bolsista no início da frase, a expectativa de que a lacuna mais próxima (de sujeito) deve ser satisfeita seria quebrada pela presença de um SN a caloura como nas frases do tipo QOC (Que bolsista a caloura convidou no baile?). Se plausível tal hipótese, os tempos médios de leitura par ao segmento destacado deverão ser significativamente mais altos do que para esse mesmo item em posição pós-verbal. Também foi estudada de modo exploratório a influência do fator congruência semântica, discutidos em Oliveira (2017).

\subsection{Resultados e discussão}

Os tempos médios de leitura na região do sintagma determinante (nos exemplos, $a$ caloira) estão apresentados no gráfico 1:

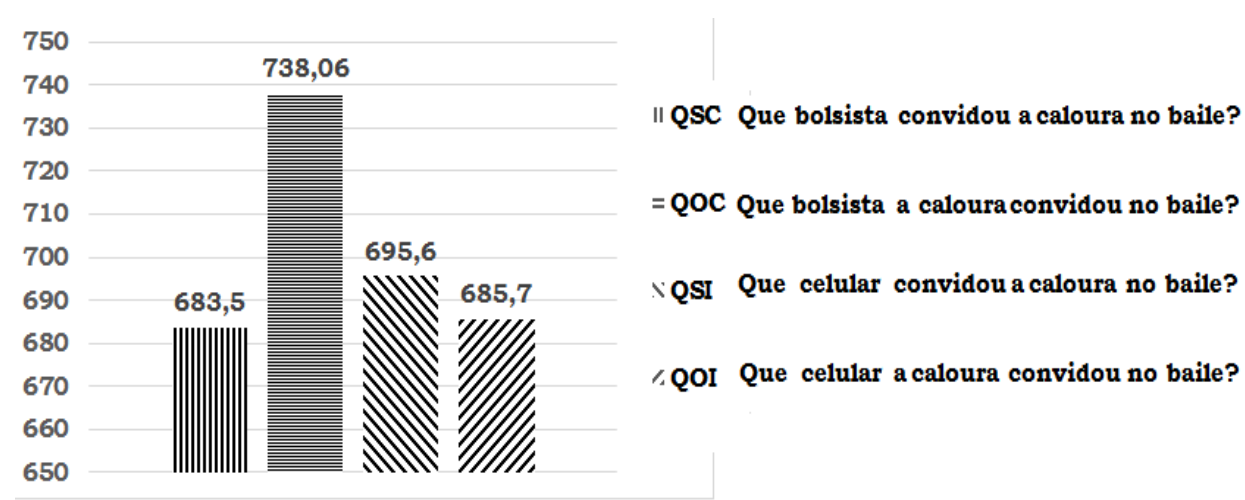

Gráfico 1: tempos médios de leitura no sintagma determinante 


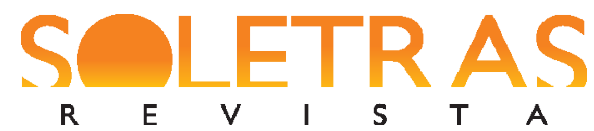

A ANOVA dos tempos médios de leitura na região do sintagma determinante revelou efeito principal de função sintática: $\mathrm{F}(1,191)=45,5 \mathrm{p}<0,000001^{* *}$, efeito principal de congruência semântica: $F(1,191)=81,1$ p<0,000001** e interação entre fatores: $F(1,191)=$ $120 \mathrm{p}<0,000001^{* *}$. O Teste $\mathrm{T}$ demonstrou também que as diferenças foram estatisticamente significativas nas principais comparações: QSC x QOC $\mathrm{t}(191)=11,48 \mathrm{p}<0,0001^{* *}$; QSC $\mathrm{x}$ QSI $\mathrm{t}(191)=3,39 \mathrm{p}<0,0008^{* *} ;$ QOC $x$ QOI $\mathrm{t}(191)=12,59 \mathrm{p}<0,0001 * *$.

Como esperado, os índices de acerto foram mais baixos para as frases com extração de objeto, que envolvem um SN interveniente preenchendo a posição que poderia ser postulada como lacuna para o sintagma-QU movido:

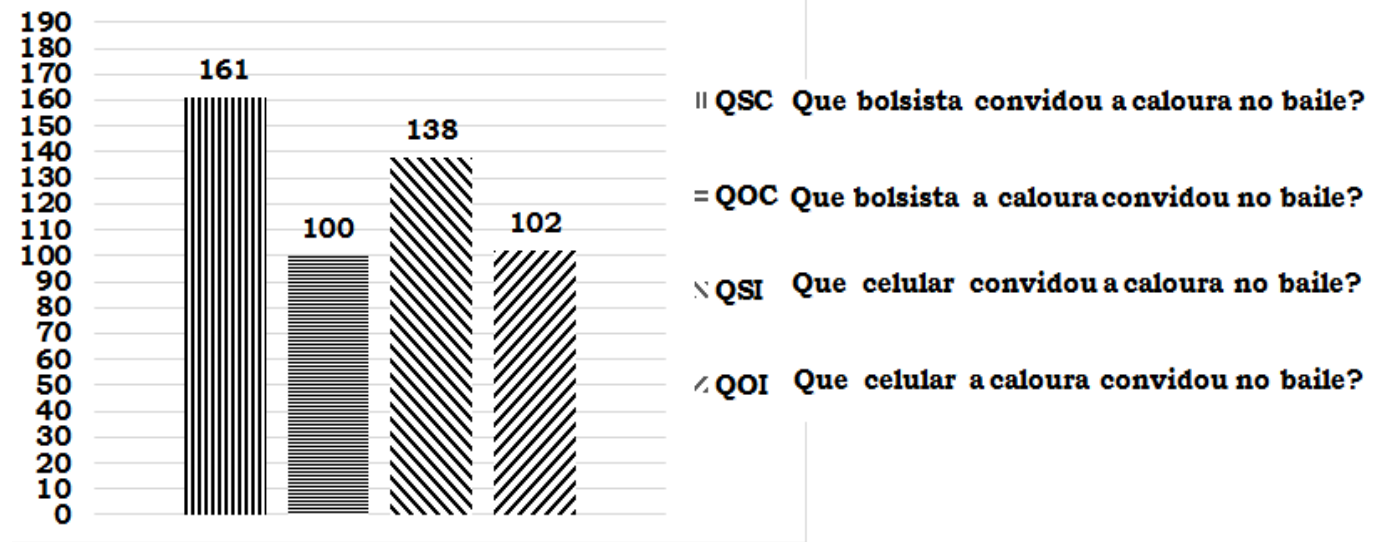

Gráfico 2: índices de acerto às perguntas interpretativas

Em geral, os resultados obtidos apontam para as hipóteses e previsões feitas: tudo indica que nas frases de objeto (QOC e QOI) o SN a caloura ocupa uma posição de provável interpretação para o elemento movido que bolsista e esse fato se reflete em menores índices de acerto e tempos de médios de leitura significativamente maiores que nas outras condições. Os índices de acertos nas perguntas interpretativas mostraram maior acurácia para as interrogativas-QU de sujeito congruentes, cuja lacuna de sujeito não estava preenchida, as quais tiveram o maior número de acertos (161 dentre 191 possibilidades). Eram computadas como ñacertoò as respostas que incidiam sobre variável dependente função sintática: ao ler uma frase como ñQue bolsista convidou a caloura no baile?ò, seguida da pergunta ñQuem 


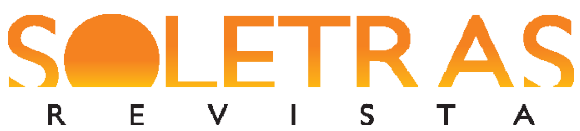

convidou?ò, as opções de resposta eram ño bolsistaò e ña calouraò. Considerando a frase lida como estando na ordem canônica SVO (Sujeito-Verbo-Objeto), a resposta correta esperada era ño bolsistaò. Além disso, os índices de acerto foram maiores nas condições congruentes, em comparação com suas contrapartes incongruentes, o que indica a influência do fator congruência semântica no processamento de frases interrogativas também no português brasileiro, ao menos em uma fase mais interpretativa, off-line.

Na medida on-line, a comparação entre os tempos médios de leitura para o segmento $a$ caloura revelou tempos significativamente mais altos, na direção esperada, sugerindo que $o$ parser dispara uma busca ativa pela primeira lacuna disponível. No caso de interrogativas-QU do PB, cuja ordem canônica é SVO, a primeira lacuna disponível seria a de sujeito. No momento em que essa lacuna é percebida como estando preenchida por outro elemento, um efeito surpresa é verificado levando ao aumento dos tempos de processamento. A leitura de um segmento como ña calouraò após o verbo (condição QSC) é demonstrou-se muito mais fácil de processar do que quando esse mesmo sintagma intervém entre um objeto interrogativo e um verbo (condição QOC). É o que se depreende do confronto entre a primeira e a segunda coluna do gráfico 1.

\section{Conclusão}

Esses resultados conduzem à interpretação de que o Efeito da Lacuna Preenchida ocorreria também na posição de sujeito em interrogativas-QU do português brasileiro, somando-se a evidências recentes (MAIA, MOURA \& OLIVEIRA, 2014, MAIA, 2014a, MAIA, 2014b, MAIA, MOURA \& SOUZA, 2016) sobre a instanciação do mesmo fenômeno em lacunas de objeto nessa língua. Novos experimentos são requeridos para conclusões mais robustas.

\section{Referências}

CHOMSKY, N. On Wh-Movement. In: CULICOVER, Peter; WASOW, Thomas, Akmajian, Adrian (Eds.). Formal Syntax. New York: Academic Press, 1977. pp. 71-132. 


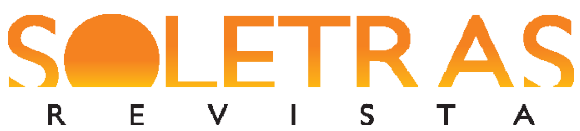

N. 33 ï 2017.1 ï FERNANDO LÚCIO DE OLIVEIRA

CLIFTON, C; Frazier, L. Comprehending sentences with long-distance dependencies. In: TANENHAUS, M.K. \& CARLSON, G. (Eds.), Linguistic structure in language Processing. Dordrecht: Kluwer Academic Press, 1989.

CRAIN, S; FODOR, J. D. (1985). How can grammars help parsers? in: DOWTY, D; KARTUNNEN, L; ZWICKY, A. (Eds.). Natural language parsing. Cambridge: Cambridge University Press, 1985.

DE VINCENZI, M. Syntactic Parsing Strategies in Italian. Dordrecht: Kluwer Academic Publishers, 1991.

FRAZIER, L. Syntactic processing: Evidence from Dutch. Natural Language and Linguistic Theory, 5: 519-560, 1987.

MAIA, Marcus; FINGER, Ingrid (Org.). Processamento da Linguagem. 1. ed. Pelotas, RS: EDUCAT, 2005. 535p. 2005.

MAIA, M; MOURA, A; OLIVEIRA, F.L. Ilusão gramatical e falibilidade seletiva no processamento de lacunas não preenchidas em português brasileiro. Revista da ABRALIN, v. xiii, p. 301-324, 2014.

MAIA, M. Efeito da Lacuna Preenchida e Plausibilidade Semântica no Processamento de Frases em Português Brasileiro. Cadernos de Letras (UFF), n. 49. 2014a.

MAIA, Marcus. Teoria gramatical, sintaxe experimental e processamento de frases: explorando efeitos do antecedente e da lacuna ativos. Revista da ABRALIN, v. 13, p. 95-120. 2014b.

MAIA, M; MOURA, A; SOUZA, M. Ilhas sintáticas e plausibilidade semântica Ï um estudo de rastreamento ocular de frases com. SCRIPTA, Belo Horizonte, v. 20, n. 38, p. 287-305, $1^{\circ}$ sem. 2016.

OLIVEIRA, Fernando Lúcio de. O Processamento da Assimetria Sujeito-Objeto em construções do tipo QU no Português Brasileiro: interrogativas e relativas. Universidade Federal do Rio de Janeiro, Faculdade de Letras, 2013. Dissertação de Mestrado em Linguística.

OLIVEIRA, F. L. O processamento da assimetria sujeito-objeto e a hipótese da assimetria como terceiro fator. Faculdade de Letras/UFRJ. Tese de doutorado, 2017 [no prelo].

RADÓ, J. Discourse effects in gap-filling. Poster presented at AMLaP-99, University of Edinburgh, 1999.

TRAXLER, MJ; PICKERING MJ. Plausibility and the processing of unbounded dependencies: An eye-tracking study. Journal of Memory and Language, 35: 454-475, 1996. 


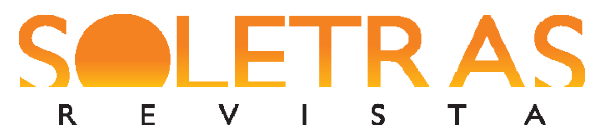

STOWE, L. Parsing whï constructions: evidence for onï line gap location. Language and Cognitive Processes, 1:227-463. 1986.

TROTZKE, A; BADER, M; FRAZiER, L. ÓThird Factors and the Performance Interface in Language Designô Biolinguistics 7: 1ї 34. 2013.

\section{Filled-Gap Effect in subject position in Brazilian Portuguese}

Abstract: This article deal with the on-line processing of subject and object WH-questions in Brazilian Portuguese. A non-cumulative self-paced Reading was carried out to investigate wheter the higher processing cost associated to the Filled-Gap Effect (Crain \& Fodor, 1985; Stowe, 1986) in object position in previous works (Maia, 2014; Maia, Moura \& Oliveira, 2014; Maia, Moura \& Souza, 2016) would be also observed in subject position of object-subject-verb (OSV) Brazilian sentences. Results showed a ñsurprising effectò in subject filled gap, indicating that this phenomenon instantiates in this language, as expected.

Keywords: Filled-Gap Effect. WH-Phrases. Subject-Object Asymmetry. Processing.

Recebido em: 30 de junho de 2017.

Aprovado em: 09 de julho de 2017. 